\title{
Breakdown Voltage Testing of Several Paper Types as Insulators for Electric Power Systems
}

\author{
Marganda Harliman Siagian $^{1}$, T. Haryono², Bambang Sugiyantoro ${ }^{3}$
}

\begin{abstract}
This research was based on high voltage equipment failure due to an increase in temperature and humidity on insulating materials. This can cause the power system reliability to decrease. On the other hand, paper is frequently found and used in everyday life. Paper can be categorized as a solid insulator even tough its use in the electric power system can be considered as minimum. This paper aimed to determine electrical insulation characteristics of three types of paper on market and to determine the amount of failed voltage and leakage current of test materials included with other factors such as temperature rise effect as well as humidity conditions in sample testing. The employed test samples were photo paper, duplex paper, and samson craft paper with a length of $7 \mathrm{~cm}$ and width of $7 \mathrm{~cm}$ with different thickness for each paper type. Tests were carried out with two paper conditions, i.e. paper was soaked in Shell Diala B oil and was not soaked in Shell Diala B oil, so that the significance of the oil on the paper used as an ingredient in testing could be known. The test results showed that temperature and humidity affected dielectric strength magnitude and test sample leakage current value. In addition, it was also found that test sample result impregnated with Shell Diala B had a higher dielectric magnitude compared to the unimpregnated test sample. Test samples impregnated with Shell Diala B oil had a leakage current value which tended to be smaller than the unimpregnated test sample.
\end{abstract}

Keywords - insulator, paper, dielectric strength, failed voltage, leakage current, temperature, humidity.

\section{INTRODUCTION}

Electricity is an inseparable part of human life, along with advancement of technology today, both in the industrial sector and in the household sector. Electric current can flow due to an electric power system existence, starting from generation, distribution, and also energy distribution to consumers. The electric power system runs well when given the right treatment to maintain system reliability. One component in an electric power system that can affect electricity distribution is an insulator. This isolator serves to block electric current so that it can remain on its channel. Therefore, insulators use and selection must be accurate [1]. Isolation technique is one branch of high voltage engineering studies. This study branch aims to reduce equipment insulation costs, i.e. by examining new dielectric properties until cheaper insulation materials are

\footnotetext{
${ }^{1}$ Department of Electrical and Information Engineering Universitas Gadjah Mada, Jl. Grafika No. 2, Bulaksumur, Yogyakarta 55281 (tlp: 0274-552305; fax: 0274-552305; e-mail: marganda.h.s@mail.ugm.ac.id)

${ }^{2,3}$ Lecturer, Department of Electrical and Information Engineering Universitas Gadjah Mada, Jl. Grafika No. 2, Bulaksumur, Yogyakarta 55281 (tlp: 0274-552305; fax: 0274552305; e-mail: thr@ugm.ac.id,bsg@ugm.ac.id)
}

found. Isolators in electric power systems function to separate two parts that have a voltage, a voltage section with parts connected to the ground and a buffer network that is usually made of metal embedded in the soil. Insulators can experience aging due to the influence of the surrounding environment, such as changes in temperature, weather, and solar radiation factors [2].

One of solid insulators commonly used is paper insulator. The commonly used paper insulation is kraft paper. Paper material has a small breakdown voltage value. Therefore, paper is immersed in transformer oil or motor oil to increase its breakdown value.

In this paper, a sample of several paper types easily found on the market in general, such as photo paper, duplex paper, and samson kraft paper, were used for testing. Tests were carried out with two paper conditions, i.e. the papers were greased and were not greased. The purpose of applying oil to the paper was to increase the paper breakdown level. Tests were carried out to determine breakdown voltage level and also leakage current of each tested paper type. This test could notice the temperature and humidity effect of the air around the insulator on the dielectric strength of each tested paper type. The electrical properties were more focused so that mechanical testing on paper was not carried out.

\section{OBJECTIVE}

The purpose of this study are (1) to recognize air temperature and humidity variables on failed voltage characteristics of greased and not greased papers and (2) to recognize air temperature and humidity variables on leakage current characteristics of either greased and not greased paper.

\section{THEORETICAL FRAMEWORKS}

\section{A. Insulator}

Insulator is a component/material that serves to separate the two parts that are different in voltage on an electric power system. Its function is to prevent current flow between the two parts. Insulator has a large resistance value therefore the resistivity value of an insulator is also large. A higher breakdown voltage value is along with a high resistivity of an insulator material [3].

Isolation issue is one of the important things, considering that it also relates to one of fields in engineering, i.e. economics. The use, installation, and selection of isolation must be effective and rational in a sense that isolation use must be in accordance with isolation level required by an electric power system.

An ability of an insulator to prevent the current flow occurrence between two affected parts is influenced by the 
characteristics of the insulator itself. The things affecting the breakdown voltage magnitude level of an insulator, among others are electrical properties, thermal properties, materials mechanical and chemical properties used as insulators [4].

Insulator electrical properties are very important in determining the isolation strength of the insulator itself. This property can be indicated by the insulator's dielectric strength. The intended electrical properties include resistivity, strong dielectric, dielectric loss factor, voltage during flashover and breakdown voltage [5]. If a dielectric material is supplied with a voltage, then the current flowing in the dielectric material consists of current flowing on material's surface and the current flowing through material. In general, current flowing on materials (through surface or through direct material) is infinitesimal. Value of the flowing current is a comparison between voltage value applied to material and material's resistance [5]. Current values can be obtained using (1).

$$
I=\frac{V}{R}
$$

with,

$$
\begin{aligned}
& I=\text { Flowing current (Ampere) } \\
& v=\text { Given voltage (volt) } \\
& R=\text { Dielectric Resistance (Ohm). }
\end{aligned}
$$

\section{B. Dielectric Material}

Dielectric material is a material that has a very low current conductivity or almost none. This dielectric material can be solid, liquid, or gas. When the dielectric material is in an electric field, its electrical charge does not experience movement. As a consequence, it does not cause currents such as conductor or semiconductor material; yet it merely shifts slightly from its equilibrium position which results in polarization. The polarity causes a positive charge to move towards a negative pole of the electric field, while a negative charge moves in the opposite direction (i.e. towards the electric field's positive pole). This results in an internal electric field (inside dielectric material) which causes the total number of electric fields surrounding dielectric material to decrease. This characteristic causes dielectric material to be a good insulator. Dielectric strength of insulating material is very important to determine the insulator quality that will support the electric power system performance [2]

The tested dielectric material was paper. Breakdown voltage of dielectric material can be used to calculate the material's dielectric strength value, i.e. using (2).

$$
E=\frac{V B(\text { average })}{d}
$$

with,

$$
\begin{aligned}
& E=\text { Material's dielectric strength }(\mathrm{kv} / \mathrm{m}) \\
& d \quad=\text { Distance (interval) between electrodes } \\
& V B=\text { Breakdown voltage value }(\mathrm{kV}) .
\end{aligned}
$$

\section{Breakdown Voltage}

A dielectric does not have free electrons, but electrons are bound to element nucleus forming the dielectric. Each dielectric has a power to bear electric exposure. Fig. 1 shows a dielectric material placed between two parallel plate electrodes. When the electrode is given a voltage in a direction of $V$, an electric field $(E)$ arises in the dielectric. This electric field forces electrons to separate from the bond and become free electrons. In other words, an electric field is a load that suppresses a dielectric to change its behavior into a conductor [5].

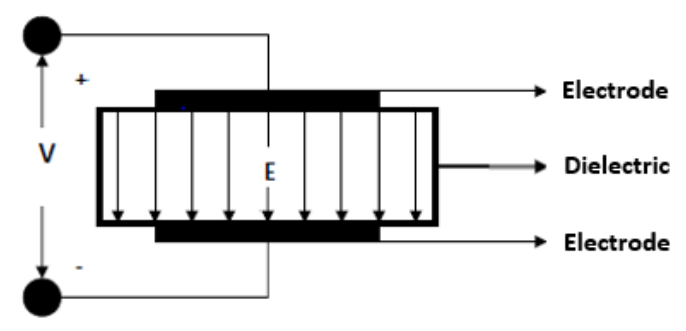

Fig. 1 Dielectric material.

If the electric exposure is carried over the limit and the exposure lasts long enough, the dielectric will conduct current or fail to carry out its function as an insulator. In this case, a dielectric is called as electrical breakdown or breakdown. The highest electrical exposure that can be borne by a dielectric without causing an electric translucent dielectric is called as dielectric strength.

If the electric exposure carried by the dielectric exceeds the limit, a chain ionization process will occur inside the dielectric which can eventually make the dielectric break through electricity. This process requires uncertain time and duration, but is statistical. The required time from the ionization to begin until electrical breakdown occurrence is called a breakdown delayed time (time lag).

\section{Leakage Current}

A leakage Current in a dielectric material occurs when in an electric fieldis applied to a dielectric material and resulting a load leap, so that free electrons become more active. This movement emerge current flows, called as leakage current (flowing on dielectric surface). It occurs when voltage need to be borne by dielectric material exceeds its ability to bear the voltage.

Excessive temperature increases in polymeric materials cause physical changes in the form of surface degradation (physical) because of several polymer chain parts movement in a cross-linking area. This physical agging can causet the heat resistance to decrease. If the temperature hitting the surface approaches transition temperature, then the connection between molecular chains will be we weaken, so that it will facilitate the molecular chains termination.

Voltage on insulation materials is a pull or pressure that must be able to be resisted by a force on the insulator material itself so as not to experience a failure. The force is the tensile forces of insulator material. In the molecular structure of insulating material, the electrons are tightly bounded by molecules and this bond is resisting the voltage. If this bond breaks off at a place, the insulation properties in that place will disappear. 


\section{Methodology}

In this test, a breakdown voltage test and leakage current were carried out, each of which consisted of two test conditions types, i.e. dry conditions without any oil and another conditions in which the papers were covered with Diala B oil transformer In each of these conditions, changes in tair emperature and humidity of the test cabinets were carried out to see the effect of these two variables on breakdown voltage and also material leakage current.

\section{A. Breakdown Voltage Test}

This tests aimed to determine the test samples (paper) resistance toward breakdown voltage. This test were carried out by providing a high voltage to the paper located between stem electrodes until a puncture isolation failure occured [6]. Circuit scheme used in this testing is shown in Fig. 2.

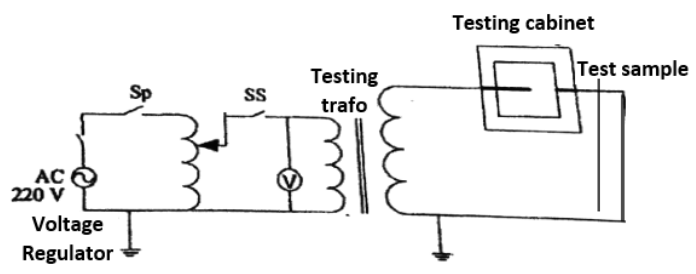

Fig. 2 Breakdown voltage testing scheme.

The test began by preparing test material first, then mounting the material between the stem electrodes. One of the electrodes was connected to a step-up transformer and the other parts were connected to the ground. A transformer was connected to control panel so that transformer output control could be carried out.Air temperature and humidity in the testing cabinet then could be adjusted.The test was carried out under a proper desired temperature and humidity by installing a thermometer and hygrometer adjecent to stem electrodes gap clamping the samples. Tests were carried out by setting variable temperatures of $27^{\circ} \mathrm{C}, 32^{\circ} \mathrm{C}, 37^{\circ} \mathrm{C}, 42^{\circ} \mathrm{C}, 47^{\circ} \mathrm{C}$, and humidity kept constant at $70 \%$. Then a setting for the next test was carried out by adjusting humidity in the test cabinet by $50 \%, 60 \%, 70 \%, 80 \%$, $90 \%$, and the temperature was kept constant at $30^{\circ} \mathrm{C}$.

When the regulator switch was turned to the right, the voltage would slowly rise until the tested paper experiencing a puncture isolation failure. The insulating material breakdown voltage value could be seen on the multimeter. The value shown in the multimeter was the voltage value on the secondary side of the step-up transformer. Therefore, this value did not need to be multiplied by step up transition ratio. After the breakdown voltage was obtained, a voltage drop was carried out by turning the regulator switch to the left until the multimeter showed a zero-voltage value. In order to conduct a breakdown voltage test on the next paper material, it was necessary to ground it by using a grounding stick to ensure the residual voltage on the high voltage equipment was lost.

The test was carried out three times for each experiment and then it was processed so that an average data from each experiment was obtained on each behavior given to test material. A flowchart of paper breakdown voltage is shown in Fig. 3.

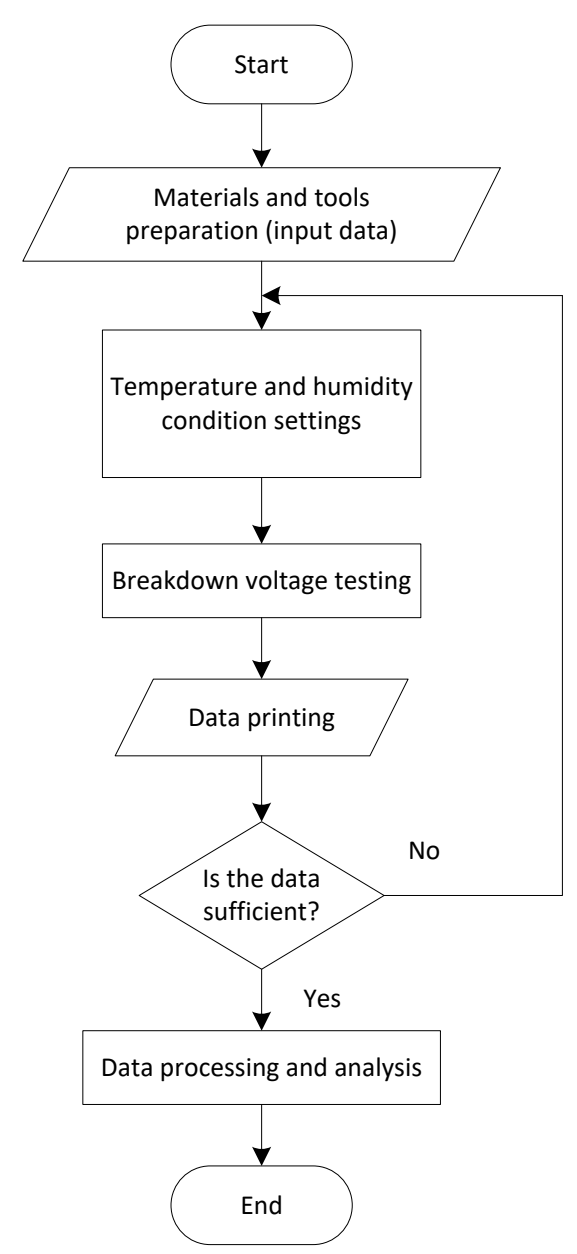

Fig. 3 Flowchart of failure voltage test.

\section{B. Leakage Current Test}

This test was carried out to determine the leakage current value in tested sample. The leakage current testing process was almost similar to the previous breakdown voltage test, except that the maximum stress value given to the material was half of the material's breakdown voltage average value in each condition. It aimed to prevent damage to the oscilloscope used to see the leakage current magnitude on the test material surface. Leakage voltage test circuit is shown in Fig. 4.

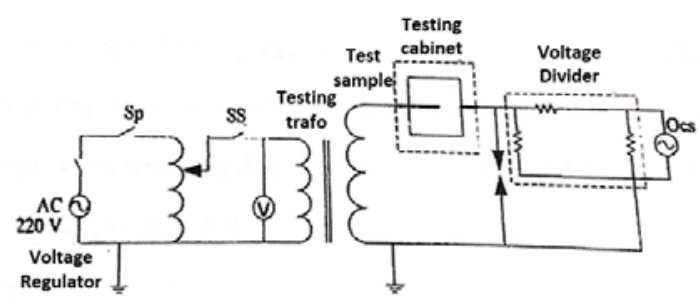

Fig. 4 Leakage current test scheme.

This test was carried out by arranging two variables, i.e. temperature and humidity. In testing the temperature effect on leakage current, temperature variable was set at temperature condition of $27^{\circ} \mathrm{C}, 32^{\circ} \mathrm{C}, 37^{\circ} \mathrm{C}, 42^{\circ} \mathrm{C}$, and $47^{\circ} \mathrm{C}$ with humidity was kept constant at $70 \%$. To test the humidity effect on 
breakdown voltage, humidity variable was set at humidity conditions of $50 \%, 60 \%, 70 \%, 80 \%$, and $90 \%$ with the temperature was kept constant at $30^{\circ} \mathrm{C}$.

After the temperature and humidity conditions were in accordance with the desired condition for testing, an input voltage of $1.8 \mathrm{kV}, 1.6 \mathrm{kV}$, and $1.4 \mathrm{kV}$ was given for duplex paper as well as Samson Kraft paper. For photo paper, the utilized input voltages were $650 \mathrm{~V}, 600 \mathrm{~V}$, and $550 \mathrm{~V}$. Each test was carried out for three times then the obtained values were averaged. Once the data was obtained, it was arranged into a table and a graph to ease the test analysis. Flowchart of leakage current test is shown in Fig. 5.

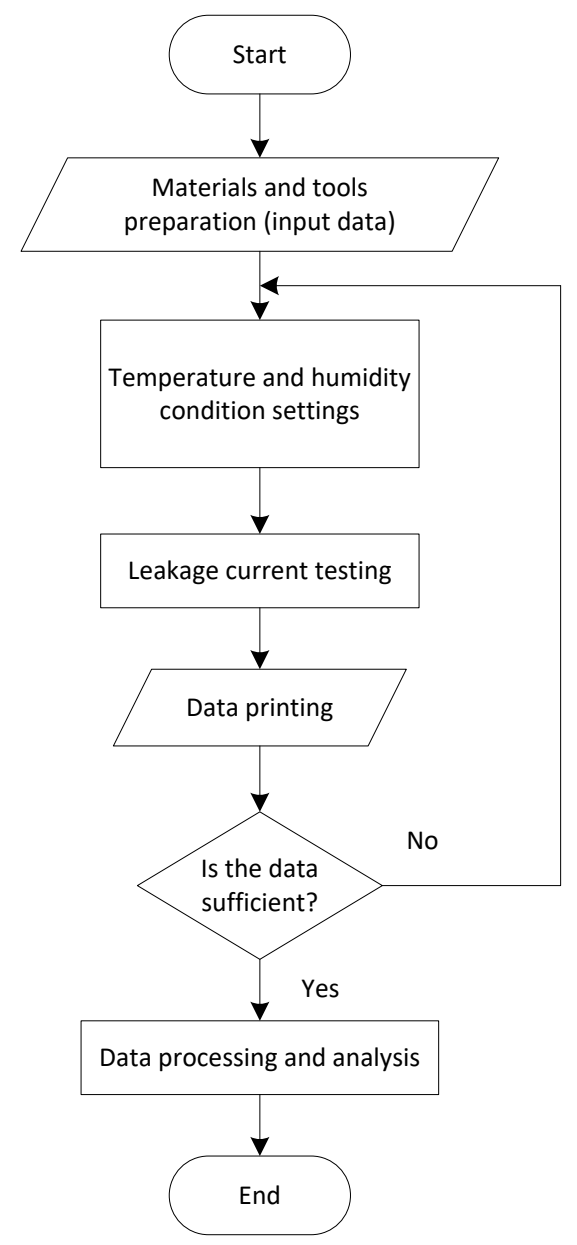

Fig. 5 Leakage current test flowchart.

\section{RESULTS AND DisCUSSION}

\section{A. Breakdown Voltage Test}

In this test, temperature and humidity effect on the dielectric strength value of tested sample was observed. The first step taken in this test was to prepare materials to be tested, i.e. photo paper, duplex paper and samson craft paper. Then, the temperature and humidity adjustments were carried out. According to the test result data on the paper which was not impregnated with Shell Diala B oil, the effect of temperature on material dielectric strength value can be shown in a form of a graph in Fig. 6 and the humidity effect is presented in Fig. 7.

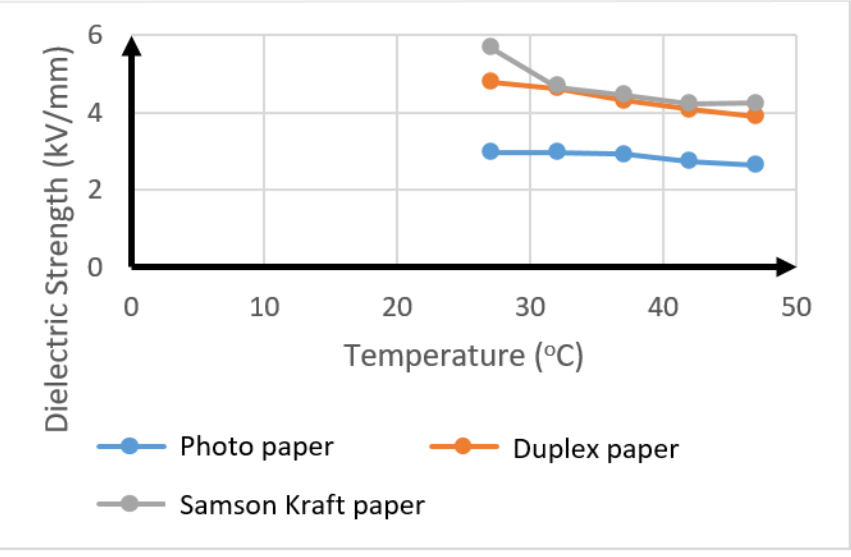

Fig. 6 Graph of temperature effect on dielectric strength of paper unimpregnated with Shell Diala B oil.

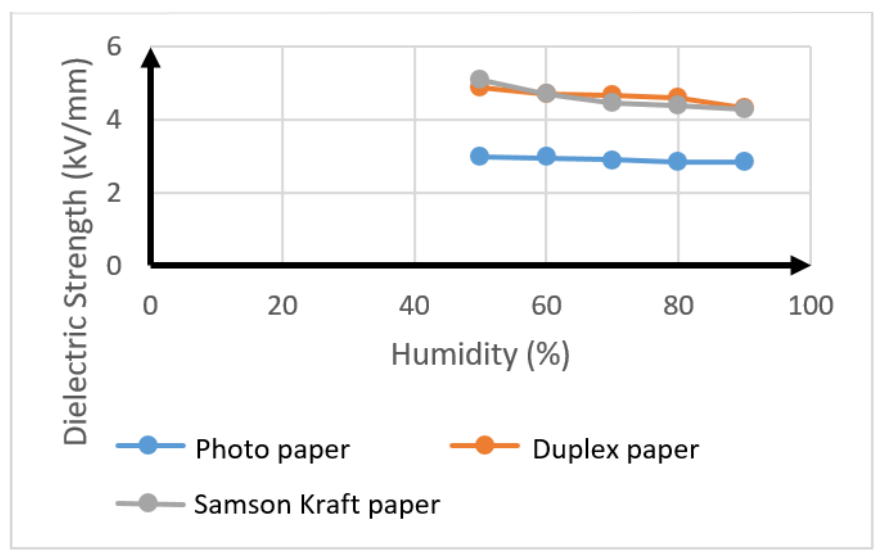

Fig. 7 Graph of humidity effect on dielectric strength of paper unimpregnated with Shell Diala B oil.

Meanwhile, for the paper impregnated with Shell Diala B oil, test result of temperature and humidity effect on test samples dielectric strength can be arranged into a graph shown in Fig. 8 and Fig. 9.

According to test result, it can be seen that air temperature and humidity in the test have a significant influence on the tested paper dielectric strength.The higher the temperaturewas, the lower the dielectric strength. When a voltage was applied to an insulating material, there was an electric field between a cathode and an anode. With the presence of this electric field, free electrons got enough energy to trigger ionization. Electrons moved toward the anode if they had enough energy. When moving, electrons collided with each other, causing more free electrons.

The higher the environment temperature was, the faster the electrons movement, so that the ionization process occured faster. This resulted in an increase in material conductivity which led to a material breakdown value that got smaller.

The higher the humidity of the air was, the lower the dielectric strength. This was due to the presence of water/dew granules emerging from water spray on the paper surface. Water is a good electric conductor, so that when an object is wet, the object resistance value decreases, so that electricity can flow more easily. Thus, the lower the paper dielectric strength is in line with the increase in humidity in the test cabinet. 


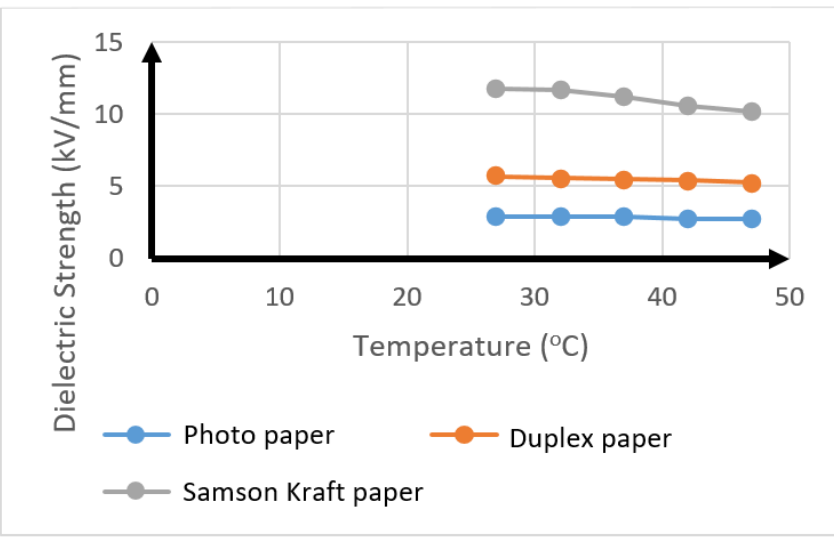

Fig. 8 Graph of temperature effect on dielectric strength of paper impregnated with Shell Diala B oil.

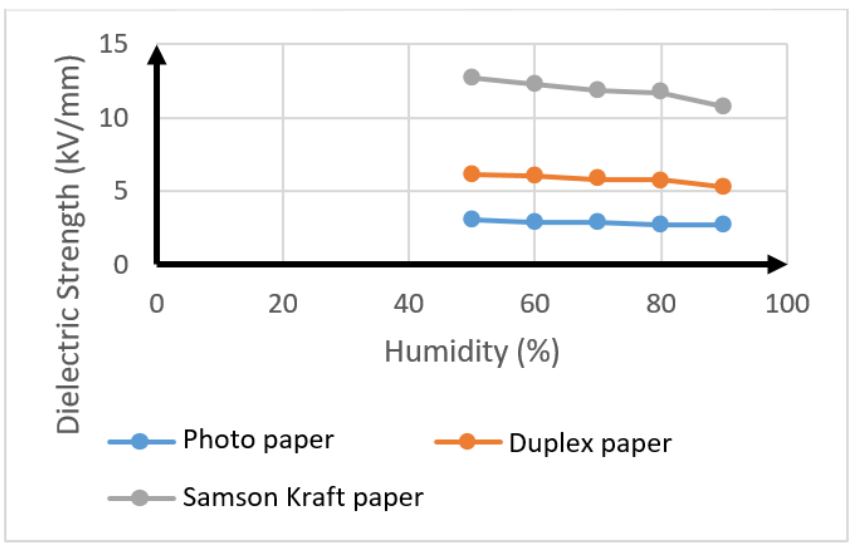

Fig. 9 Graph of humidity effect on dielectric strength of paper impregnated with Shell Diala B oil.

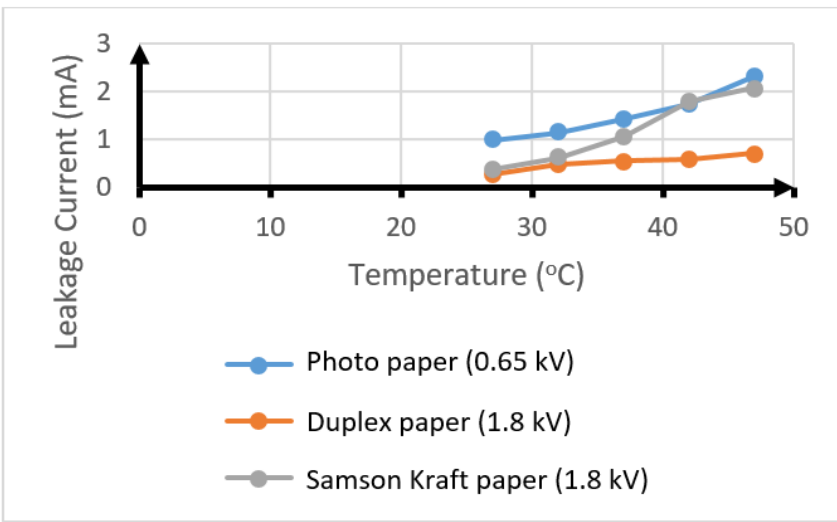

Fig. 10 Temperature effects on leakage current value of the papers unimpregnated with Shell Diala B oil.

\section{B. Leakage Current Test}

Leakage current test was carried out by varying the humidity and temperature at the time of testing, so that the temperature and humidity variations effects on the leakage current value in the test sample could be seen.

This test provided resulted in the form of a signal on an oscilloscope. On the oscilloscope, the rms voltage was obtained. The rms voltage value on the oscilloscope was changed into leakage current value by multiplying rms voltage on the oscilloscope with a multiplier factor from PSIM simulation result which was 0.00021 .

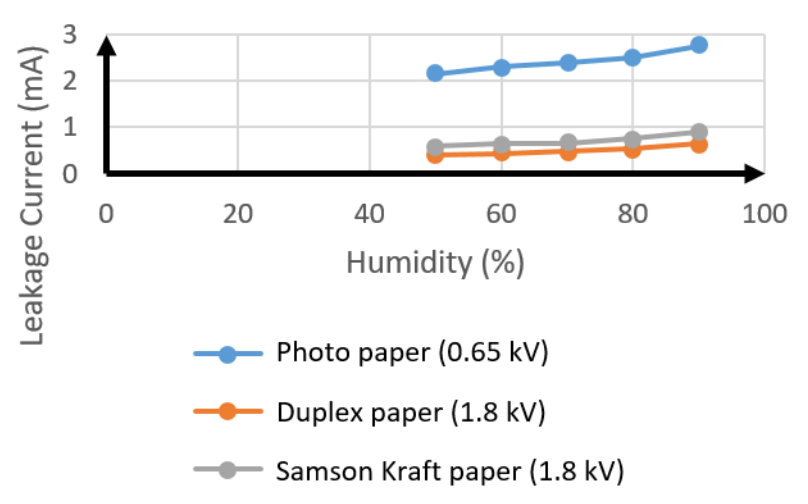

Fig. 11 Humidity effects on leakage current value of the papers impregnated with Shell Diala B oil.

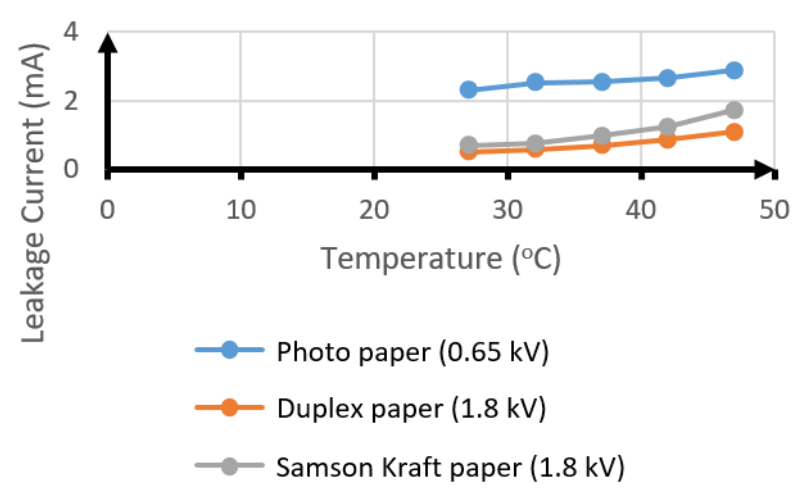

Fig. 12 Temperature effects on leakage current value of the papers unimpregnated with Shell Diala B oil.

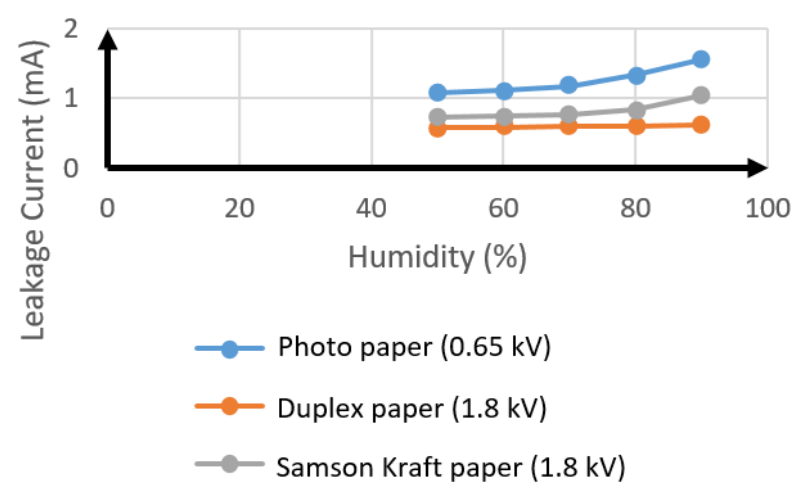

Fig. 13 Humidity effects on leakage current value of the papers impregnated with Shell Diala B oil.

According to leakage current test results, the temperature effects on leakage current of papers unimpregnated with Shell Diala B oil can be displayed in a form of a graph in Fig. 10 and the humidity effects on the leakage current value are shown in Fig. 11.

While for paper impregnated with Shell Diala B oil, test results of temperature and humidity effects on test sample 
leakage current value are arranged into a graph presented in Fig. 12 and Fig. 13.

According to test results, it can be seen that temperature rise is in line with the leakage current value changing. If the temperature rises, the leakage current value is also getting bigger. When a voltage is applied to an insulating material, there is an electric field between the cathode and anode. With the presence of this electric field, free electrons got enough energy to trigger ionization. Electrons moved toward the anode if they had enough energy. When moving, electrons collided with each other, causing more free electrons.

The higher the environment temperature was, the faster the electrons movement, so that the ionization process occured faster. This results in increased material conductivity which leads to an increase in the electric current flowing in the larger material. It can also be seen that every increase in humidity results in the increasing leakage current value in the sample.It is due to water droplets inside the test value that appear due to water spraying into test cabinet to raise air humidity in test cabinet. Objects exposed to water have a low resistance value so electricity easily flows and the current value is higher when compared to the air condition which is slightly dry.

\section{CONCLUSION}

Based on the analysis and discussion results that has been carried out, conclusion can be drawn as follows. Temperature has an effect on the dielectric strength of each paper type used in this test. The dielectric strength of each paper type decreases. Paper impregnation with Shell Diala B oil gave good results on the three tested paper types. Each type of paper soaked for one day and one night with Shell Diala B oil experinced an increased dielectric strength. The increase in temperature affects the test sample dielectric strength value. The higher the temperature is, the smaller the test sample dielectric strength.

Humidity affects the test sample dielectric strength. The higher the humidity of the air was, the lower the dielectric strength.

Temperature and humidity also affected the leakage current of paper samples used in testing. The temperature rise is in line with the increase in leakage current experienced by the papers in testing. The increase in humidity of the test cabinet (environment) resulted in a greater occuring leakage current. Shell Diala B oil impregnation also affected the leakage currents value which are affected by temperature and humidity. The largest leakage current value experinced by each paper which was not impregnated with Shell Diala B oil was bigger than the leakage current value of paper samples which were firstly soaked in Shell Diala B oil.

\section{REFERENCES}

[1] W. Purwanto, "Karakteristik Isolasi Kertas Setelah Direndam pada Minyak Isolasi," Thesis, Universitas Gadjah Mada, Yogyakarta, Indonesia, 2012.

[2] A. Arismunandar, Teknik Tegangan Tinggi, Jakarta, Indonesia: Prandnya Paramita, 2001

[3] M.A. Prayudha, "Kaca Film Mobil Sebagai Bahan Isolator Listrik," Thesis, Universitas Gadjah Mada, Yogyakarta, Indonesia, 2013.

[4] M.S. Naidu \& V. Kamaraju, High Voltage Engineering, $2^{\text {nd }}$ Edition, New Delhi, India: MCGraw-Hill, 1995.

[5] B.L. Tobing, Dasar Teknik Pengujian Tegangan Tinggi, Jakarta, Indoensia: PT. Gramedia Pustaka Utama, 2003.

[6] "Panduan Praktikum Teknik Tegangan Tinggi," Laboratorium Teknik Tegangan Tinggi Departemen Teknik Elektro dan Teknologi Informasi Fakultas Teknik, Universitas Gadjah Mada, Yogyakarta, 2017. 